\title{
Experimental investigation on barite sag under flowing condition and drill pipe rotation
}

\author{
Saeed Zaker ${ }^{1} \cdot$ Pegah Sarafzadeh ${ }^{2} \cdot$ Amin Ahmadi $^{3} \cdot$ Seyyed Hamid Esmaeili-Faraj ${ }^{4} \cdot$ Roohollah Parvizi $^{5}$
}

Received: 13 June 2020 / Accepted: 21 August 2020 / Published online: 2 September 2020

(c) The Author(s) 2020

\section{Abstract}

Using drilling fluids with optimum density is one of the most important approaches to stabilize the pressure of the bottom formation and prevent blowout through the drilling process. One of the common methods for this purpose is adding some additives with high specific gravity to the drilling fluid to tune its density. Among the possible chemicals, barite and hematite with the density of 4.2 and $5.2 \mathrm{~g} / \mathrm{cc}$ are the most common additives. Unfortunately, although the application of these additives is advantageous, they have some drawbacks which the most important one is separation and settlement of solid phase called barite sag. The barite sag comes from barite, or other dense materials particles deposition resulted in undesired density fluctuations in drilling fluid can lead to mud loss, well control problems, poorly cementing and even pipe sticking which occurs in severe cases. With respect to these concerns, the current investigation is concentrated to obtain the relation between the dynamic conditions such as flow rate $(0.308$ and $0.19 \mathrm{l} / \mathrm{s})$ and deviation angles of $30^{\circ}, 45^{\circ}, 60^{\circ}$ and $90^{\circ}$ and barite sag phenomenon through a flow loop equipment. Besides, the effect of drilling string rotational speed ( $70 \mathrm{rpm})$ on the barite deposition is investigated. The results not only indicate that increasing the flow rate from $0.19 \mathrm{l} / \mathrm{s}$ to $0.308 \mathrm{l} / \mathrm{s}$ can reduce the deposition rate, but also increasing the deviation angle from 45 to $60^{\circ}$ enhance the barite deposition to its maximum value.

\section{Graphic abstract}

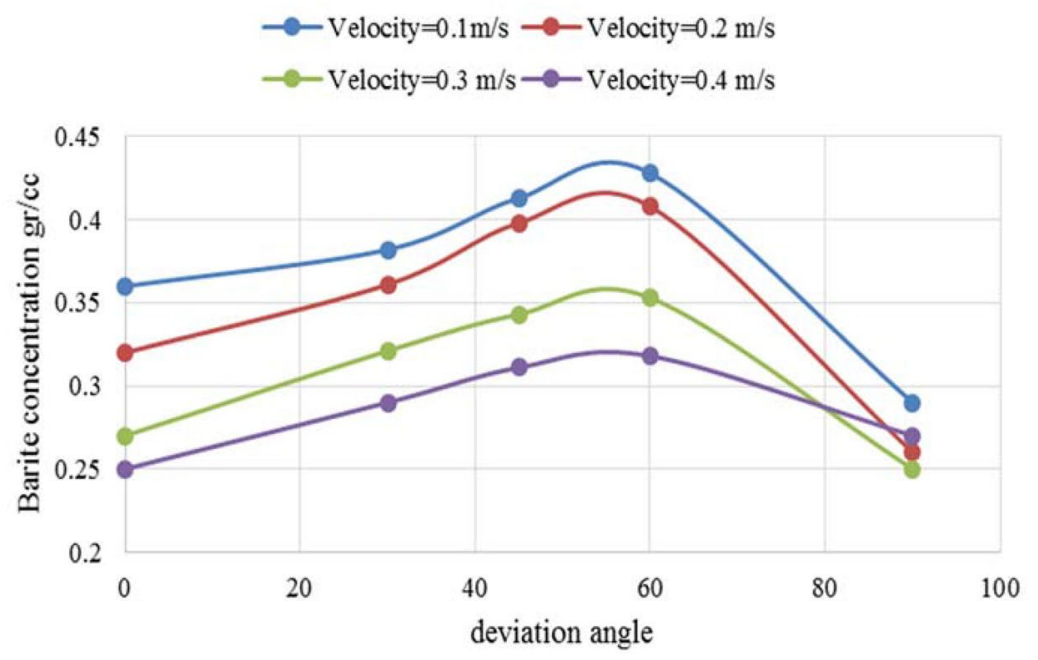

Change in the amount of particles deposited in the circular space as a function of flow rate and deviation angle

Keywords Barite settlement · Annular space $\cdot$ Dynamic condition $\cdot$ Barite sag

Roohollah Parvizi

rh_parvizi@yahoo.com

Extended author information available on the last page of the article 


\section{Introduction}

Drilling is one of the most critical hazardous processes in the oil industry which its safety is an undeniable desire moving the researchers toward drilling fluid with controlled morphologies which can guarantee the safety and quality of this process. In detail, as the drilling process going on, accumulation of cuttings produced during drilling operation can cause drilling pipes to be stuck which in severe conditions the drilling string can be cut off and the operation aborted. In this way, it is vital for any drilling process to evacuate these cuttings to avoid such a catastrophic event. On the other hand, solubility of borate particles is the other problem which can be eliminated in some extend if oil-based muds utilize, while itself can appear a problem known as barite sag. Unfortunately, although barite sag is a well-known problem, there are limited tools which can help petroleum men to reliably detect this problem. In this way, several investigations have performed to find the effect of weight mud, pressure of vertical pipe, torque, decrease and increase in mud volume and changes in rheological properties, but no consistent results make it necessary to perform more systematic investigations regarding this phenomenon for more clarification (Mirjevardi, 2017). For example, Hanson et al. (1990) and Saasen et al. (1995) studied the precipitation of barite particles in angular tubes to find a mechanism for the barite particles sedimentation and claimed that it is similar to blood cells deposition. Besides, the experiments performed by Skalle et al. (1999) show that the barite sag phenomenon can occur under both dynamic and static conditions although the precipitation boosted under dynamic condition. Moreover, the results reported from a systematic investigation performed by Nguyann et al. (2009) with the assist of a stream loop apparatus revealed that it would be possible to substantially reduce the barite sag phenomenon if the drill string rotational speed set as a low value. Also, Yousef Kashkah (2013) investigated the effect of different operating parameters on barite sag using laboratory equipment and then compared it with field results. The results show that one of the most effective parameters on barite sag is the deviation angle which would introduce its ultimate effect if deviation angle changed between $45^{\circ}$ and $60^{\circ}$. Furthermore, Roohi (2011) studied a new experimental method to evaluate static sag in without using weight of the samples which is a tedious and costly approach. In detail, he proposed a method which was based on the pressure measurement at the desired depth at the laboratory scale and then correlates it to barite sag which directly can reduce the required time and cost due to its simplicity.

On the other side, since experimentation is not always possible and even would be a costly and time-consuming approach in some cases, using simulations and modeling approaches is the main objective of some research groups. For example, Hashemian et al. (2014) simulated the barite deposition considering different parameters including vortex currents on the deposition of barite micro-particles in the rotation of the drilling string, as well as the creation of a spiral boundary layer due to the conformity of the axial flow of the fluid with the radial flow due to the rotation of the drilling fluid. Also, Kabanda (2017) studied a numerical simulation regarding barite sag through tubes and currents. The simulation results indicated that the barite sag mostly occurred at low velocity, a non-rotating drilling pipe and a centrifugal tube. Moreover, Ribeiro (2017) proposed a two-simple-stage and practical model based on the governing equations to describe the deposition of particles in drilling fluids. The main hypothesis behind the proposed method was the use of materials for the weight gain which causes various problems such as decreasing the hydrostatic pressure of the muds. Regarding the aforementioned shortcomings and problems regarding the barite sag phenomenon, an experimental approach using homemade equipment was used to examine the effect of different operating parameters including the deviation angle, density of drilling fluid, concentrations of barite and flow rate on barite sag since no consistent results are reported regarding this destructive phenomenon based on the best knowledge of the authors.

\section{Experimental procedure}

In the first stage, the sample drilling fluid was prepared and dispatched into the containment reservoir. After that, a specific amount of barite particles was added and well mixed using an embedded rotary mixer installed inside the tank and a fluid jet to ensure about proper mixing. After fluid preparation, the fluid was injected into the flow loop using a mud pump (with maximum flow rate of $150 \mathrm{l} / \mathrm{s}$ ) concomitant with a proper bypass flow rate. This excess flow through a bypass returns to the reservoir using a nozzle to enter the fluid into the tank in jet condition which can help the system for better mixing and agitation by introducing a kind of turbulence regime which would retard the precipitation of barite. In this stage, no precipitation of particles would be occurred due to the turbulent flow existed in the annular part. When the high-speed flow is stabilized within the annular portion, the input valve is closed to the annular portion, and the device is kept at a dynamic or static state. At this point, the barite particles begin to settle in the circular space, and this sedimentation continues until it reaches its ultimate value. At this point, pressure changes along the annular portion were continuously recorded as a function of time to measure the barite deposition rate. The worth mentioning point is that a 
flow rate with a maximum discharge pump capacity in the annular portion was used to perform dynamic and sag load tests. At this point, as the injected fluid stabilized, a constant injection rate with slow dispatching within the circular part would be provided. Under a slow stream, a constant settled bed of barite would be formed at the bottom of the tube and throughout it. At this point, it would be possible to find the barite concentration variation using a continuous sampling from the pipes through a dynamic operation. This procedure was repeated for all the different injection rates and other operating conditions with including rotational speed of the drilling string acting as a drill rotation simulator (Fig 1).

\section{Results and discussion}

\section{Effect of barite concentration on rheological behavior of drilling fluid}

In the first stage, an inverse emulsion drilling fluid was prepared to be injected into the flow loop (see Tables 1 and 2).

Prior to any experimentation, the rheological properties of the prepared solutions were measured using Fan rotating viscometer (USA) (see Table 3 and Fig. 2) as a function of barite concentration. The obtained results tabulated in Table 3 revealed that as the barite concentration was increased, the rheological behavior of the mud was changed due to an increase in the internal friction of the fluid caused by the presence of particles. In detail, due to an increase in internal friction of particles, the internal stress of the fluid increases consequently enhances the fluid viscosity obeying the Herschel Buckley and Bingham models behavior.

\section{Effect of dynamic parameters on barite Sag}

In the next stage, the effects of different parameters including flow rate and deviation angle were measured on the

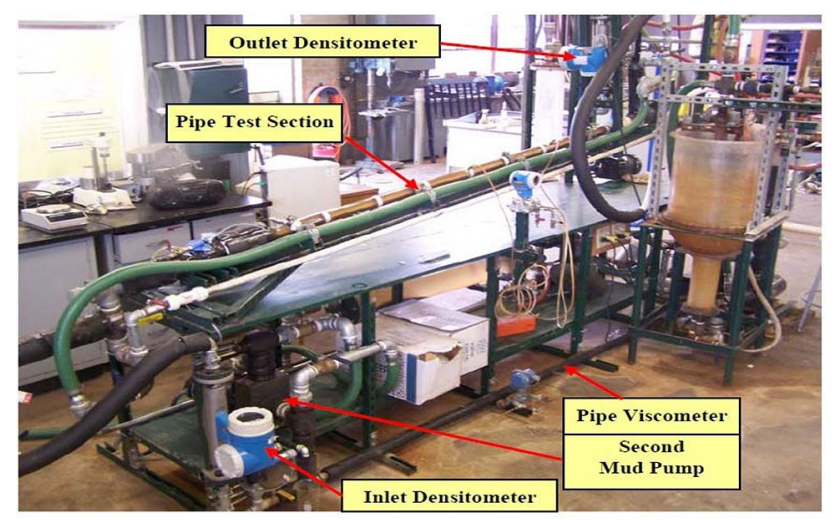

Fig. 1 Used loop flow equipment [8]
Table 1 The percentage of drilling fluid components

\begin{tabular}{ll}
\hline Components name & Concentration \\
\hline Water & $45 \% \mathrm{vol}$ \\
Oil & $45 \% \mathrm{vol}$ \\
Primary emulsifier & $5 \% \mathrm{vol}$ \\
Secondary emulsifier & $5 \% \mathrm{vol}$ \\
Lime & $6 \% \mathrm{wt}$ \\
CMC & $5 \% \mathrm{wt}$ \\
Barite & $25 \% \mathrm{wt}$ \\
\hline
\end{tabular}

barite sag phenomenon (see Table 4). Mining into the results revealed that increasing the flow rate from 0.190 to $0.308 \mathrm{l} / \mathrm{s}$, while the deviation angle and rotational speed were held constant at $45^{\circ}$ and $0 \mathrm{rpm}$, respectively, can lead to a reduction in the bottom concentration (Table 5).

Besides, the results revealed that increasing the rotational speed to a value of $70 \mathrm{rpm}$ can retard the particle precipitation based on the measured concentration of the drilling fluid at the bottom section of the equipment. On the other hand, closer examination in the results obtained for the densities of top and bottom streams revealed that introducing rotation can reduce the density of both top and bottom streams which may be due to prevention of particle precipitation (see Figs. 3 and 4). In detail, in the presence of the drilling string rotation, as well as the axial flow of the fluid, a spiral velocity distribution would be existed in the circular space which prevents the precipitation of barite particles. Moreover, depicted results in Fig. 3 reveal that it would be the accumulation of particles as a function of time leading to an enhancement in both top and bottom concentrations although it reaches a plateau after a while. At this point, the rate of barite particle settlement into the tube or the circular space is equal to the particle rising rate of the particles providing a kind of equilibrium.

This observed trend can be related to this fact that as the barite particles deposited, the effective diameter of the circular space decreases and consequently increases the effective fluid velocity if the flow rate is kept constant. At this time, the passing flow rate on the surface of the deposited barite bed increases which can accelerate the removal of barite from the bed and keep constant the concentration of particles

Table 2 Fluid properties

\begin{tabular}{ll}
\hline Properties & Value \\
\hline Fluid plastic viscosity & $10 \mathrm{cp}$ \\
Fluid density containing barite & $2.4 \mathrm{~g} / \mathrm{cc}$ \\
Diameter of barite particles & $75 \mathrm{~g} / \mathrm{cc}$ \\
The density of barite particles & $4.2 \mathrm{~g} / \mathrm{cc}$ \\
Tension subdued fluid & $6 \mathrm{pa}$ \\
\hline
\end{tabular}


Table 3 The rheological properties of drilling fluid as a function of barite concentration

\begin{tabular}{|c|c|c|c|c|c|c|c|c|c|c|c|c|}
\hline \multicolumn{4}{|c|}{$0.1 \mathrm{~g} / \mathrm{cc}$ barite } & \multicolumn{3}{|c|}{$0.12 \mathrm{~g} / \mathrm{cc}$ barite } & \multicolumn{3}{|c|}{$0.12 \mathrm{~g} / \mathrm{cc}$ barite } & \multicolumn{3}{|c|}{$0.25 \mathrm{~g} / \mathrm{cc}$ barite } \\
\hline $\mathrm{rpm}$ & SS & SR & Theta & SS & SR & Theta & SS & SR & Theta & SS & SR & Theta \\
\hline 3 & 1.06 & 5.13 & 1 & 2.65 & 5.109 & 1 & 2.65 & 5.109 & 4 & 6.36 & 5.109 & 6 \\
\hline 6 & 3.18 & 10.3 & 3 & 5.3 & 10.22 & 3 & 5.3 & 10.22 & 8 & 10.6 & 10.22 & 10 \\
\hline 100 & 8.48 & 171 & 8 & 11.7 & 170.3 & 8 & 11.7 & 170.3 & 16 & 19.1 & 170.3 & 18 \\
\hline 200 & 14.8 & 342 & 14 & 18 & 340.6 & 14 & 18 & 340.6 & 22 & 26.5 & 340.6 & 25 \\
\hline 300 & 27.6 & 513 & 26 & 30.7 & 510.9 & 26 & 30.7 & 510.9 & 33 & 38.2 & 510.9 & 36 \\
\hline 600 & 43.5 & 1026 & 41 & 50.9 & 1022 & 41 & 50.9 & 1022 & 54 & 63.6 & 1022 & 60 \\
\hline
\end{tabular}

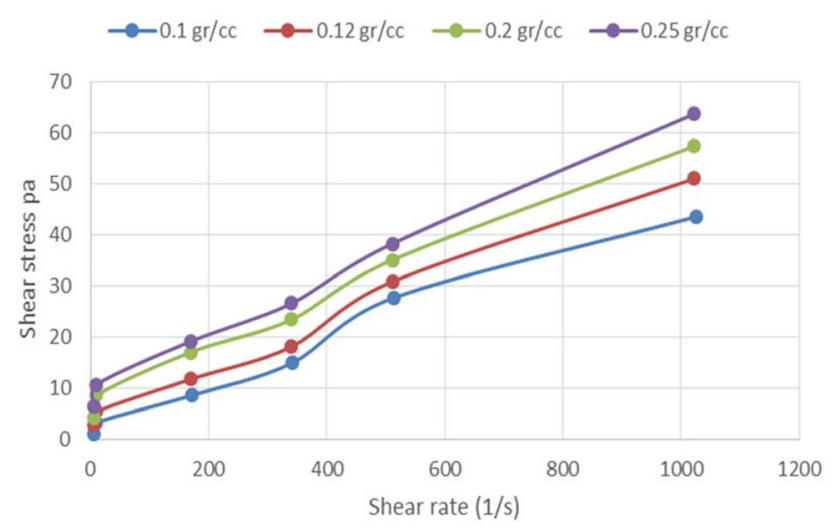

Fig. 2 Drilling mud shear stress change as a function of shear rate

Table 4 The results of dynamic investigation under temperature of $38{ }^{\circ} \mathrm{C}$

\begin{tabular}{|c|c|c|c|c|c|}
\hline Time (min) & $C_{\text {top }}(\mathrm{g} / \mathrm{cc})$ & $C_{\text {bottom }}(\mathrm{g} / \mathrm{cc})$ & $\begin{array}{l}\text { Flow rate } \\
(1 / s)\end{array}$ & RPM & $\begin{array}{l}\text { Devi- } \\
\text { ation } \\
\text { angle }\end{array}$ \\
\hline 0 & 2.40 & 2.46 & 0.308 & 0 & 45 \\
\hline 10 & 2.06 & 2.88 & & & \\
\hline 20 & 1.73 & 3.20 & & & \\
\hline 30 & 1.52 & 3.40 & & & \\
\hline 40 & 1.50 & 3.43 & & & \\
\hline 0 & 2.40 & 2.46 & 0.190 & 0 & 45 \\
\hline 10 & 1.86 & 2.88 & & & \\
\hline 20 & 1.33 & 2.52 & & & \\
\hline 30 & 1.18 & 3.81 & & & \\
\hline 40 & 1.10 & 3.93 & & & \\
\hline 0 & 2.40 & 2.46 & 0.308 & 70 & 45 \\
\hline 10 & 2.26 & 2.68 & & & \\
\hline 20 & 1.93 & 2.98 & & & \\
\hline 30 & 1.72 & 3.18 & & & \\
\hline 40 & 1.65 & 3.27 & & & \\
\hline 0 & 2.40 & 2.46 & 0.190 & 70 & 45 \\
\hline 10 & 2.06 & 2.58 & & & \\
\hline 20 & 1.53 & 3.22 & & & \\
\hline 30 & 1.48 & 3.58 & & & \\
\hline 40 & 1.34 & 3.73 & & & \\
\hline
\end{tabular}

Table 5 The results of dynamic investigation under temperature of $38{ }^{\circ} \mathrm{C}$

\begin{tabular}{|c|c|c|c|c|c|}
\hline Time (min) & $C_{\text {top }}(\mathrm{g} / \mathrm{cc})$ & $C_{\text {bottom }}(\mathrm{g} / \mathrm{cc})$ & $\begin{array}{l}\text { Flow rate } \\
(1 / s)\end{array}$ & RPM & $\begin{array}{l}\text { Devi- } \\
\text { ation } \\
\text { angle }\end{array}$ \\
\hline 0 & 2.40 & 2.46 & 0.308 & 0 & 60 \\
\hline 10 & 2.93 & 2.88 & & & \\
\hline 20 & 3.27 & 3.20 & & & \\
\hline 30 & 3.51 & 3.40 & & & \\
\hline 40 & 3.53 & 3.43 & & & \\
\hline 0 & 2.40 & 2.46 & 0.190 & 0 & 60 \\
\hline 10 & 1.66 & 2.93 & & & \\
\hline 20 & 1.23 & 3.72 & & & \\
\hline 30 & 1.12 & 3.95 & & & \\
\hline 40 & 1.01 & 4.08 & & & \\
\hline 0 & 2.40 & 2.46 & 0.308 & 70 & 60 \\
\hline 10 & 2.19 & 2.73 & & & \\
\hline 20 & 1.82 & 3.05 & & & \\
\hline 30 & 1.64 & 3.25 & & & \\
\hline 40 & 1.56 & 3.38 & & & \\
\hline 0 & 2.40 & 2.46 & 0.190 & 60 & 70 \\
\hline 10 & 2.16 & 2.78 & & & \\
\hline 20 & 1.48 & 3.30 & & & \\
\hline 30 & 1.38 & 3.65 & & & \\
\hline 40 & 1.31 & 3.81 & & & \\
\hline
\end{tabular}

at the bottom of the system. On the other side, controlling the maximum concentration of barite at the end of the tube is vital since formation of the barite bed in this area can manipulate the functionality of drilling string and never must be exceeded a critical mass.

A closer examination in Fig. 3 shows the results of density changes for the rotational speed of the $70 \mathrm{rpm}$ comparing with rotational speed of $0 \mathrm{rpm}$. As can be seen, the drilling string rotation decreases the rate of variation in the concentration of barite, which indicates a change in the fluid flow geometry. The reason behind this phenomenon can be due to this fact that as the drilling string rotated, the drag or lift force influences the particles and causes the particles to separate from the surface and suspended in the fluid which directly affects the deposition rate of barite. Finally, as can 


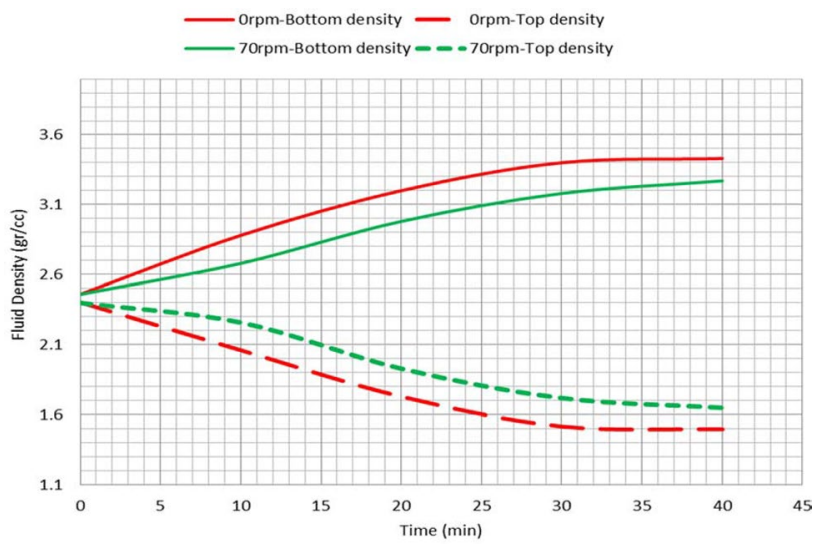

Fig. 3 Changes in the concentration of barite particles in the upstream and downstream of the circulating loop (flow rate of $0.308 \mathrm{l} / \mathrm{s}$ and deviation angle of $45^{\circ}$ )

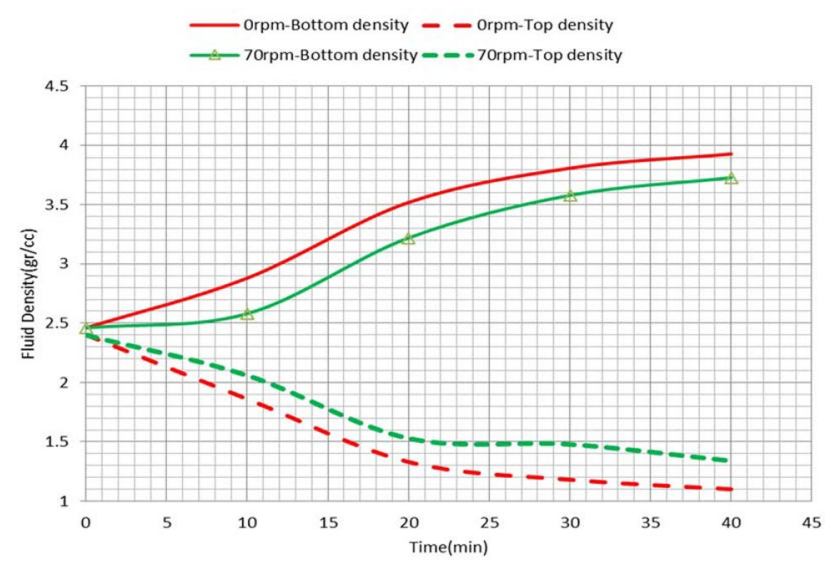

Fig. 4 Changes in the concentration of barite particles in the upstream and downstream of the circulating loop (flow rate of $0.190 \mathrm{l} / \mathrm{s}$ and deviation angle of $45^{\circ}$ )

be seen, the maximum rate of deposited barite at the end of the pipe for a condition with no rotational speed and velocity of $0.308 \mathrm{~m} / \mathrm{s}$ is equal to $3.43 \mathrm{gr} / \mathrm{cc}$, while in the presence of rotational speed of $70 \mathrm{rpm}$, this concentration was reduced to value of about $3.27 \mathrm{gr} / \mathrm{cc}$.

A closer examination in the results tabulated in Table 4 and depicted in Figs. 3 and 4 revealed that similar trend can be observed for rotational speed of $70 \mathrm{rpm}$ regarding top and bottom concentrations. Besides, the results also revealed that introducing rotational speed can reduce the rate of variation in the concentration of barite, which indicates a change in the fluid flow geometry. Moreover, the findings revealed that the maximum rate of depositing barite at the end of the pipe for a case which no speed was introduced is about $3.93 \mathrm{~g} / \mathrm{cc}$ for flow rate of $0.19 \mathrm{l} / \mathrm{s}$, while for flow rate of $0.19 \mathrm{l} / \mathrm{s}$ with rotational speed of $70 \mathrm{rpm}$, the barite deposition was equal to $3.73 \mathrm{~g} / \mathrm{cc}$. On the other hand, investigations revealed that

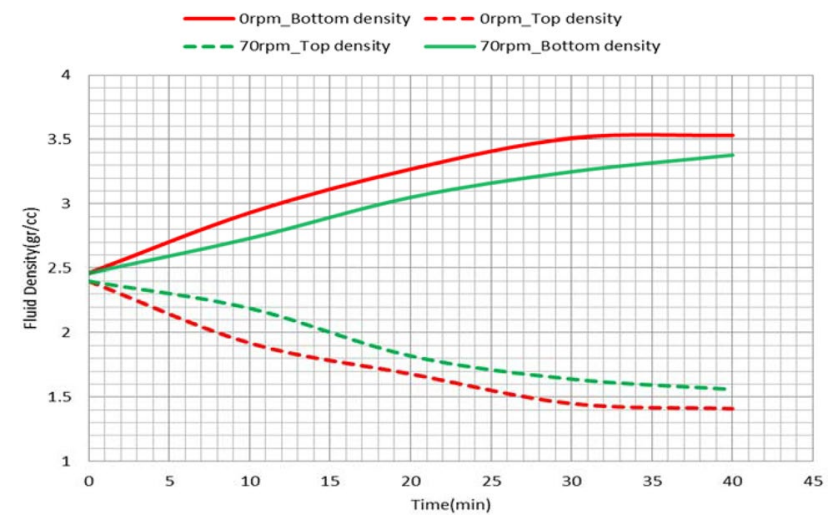

Fig. 5 Changes in the concentration of barite particles in the upstream and downstream of the circulating loop (flow rate of $0.308 \mathrm{l} / \mathrm{s}$ and deviation angle of $60^{\circ}$ )

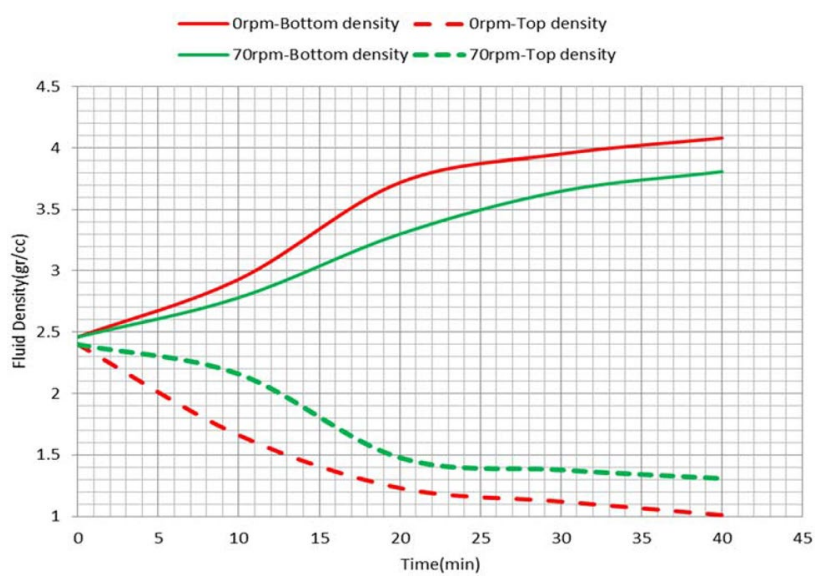

Fig. 6 Changes in the concentration of barite particles in the upstream and downstream of the circulating loop (flow rate of $0.190 \mathrm{l} / \mathrm{s}$ and deviation angle of $60^{\circ}$ )

not only introducing rotational speed can reduce the deposition of barite particles, but also increasing the flow rate from 0.19 to $0.308 \mathrm{l} / \mathrm{s}$ can reduce the barite particle deposition to value of about $1.5 \mathrm{~g} / \mathrm{cc}$. In the next stage of this investigation, the deviation angle was changed to $60^{\circ}$, while the other parameters such as flow rate and rotational speed were kept unchanged. Similar to the first series of experiments, it seems that introducing the deviation angle of $60^{\circ}$ concomitant with rotational speed of $70 \mathrm{rpm}$ can reduce the amount of barite particle deposition. More investigations also demonstrated that the maximum deposition rate for barite can be obtained for flow rate of $308 \mathrm{l} / \mathrm{s}$ which is equal to $3.93 \mathrm{~g} / \mathrm{cc}$ as the rpm is zero, while this value can be reduced to $3.73 \mathrm{~g} /$ $\mathrm{cc}$ for rotational speed of $70 \mathrm{rpm}$ and the flow rate was kept constant at 0.308 1/s (see also Figs. 5 and 6).

Finally, the effects of flow rate and deviation angle on barite particle precipitation were examined (see Fig. 7). As it

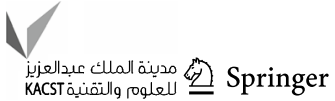




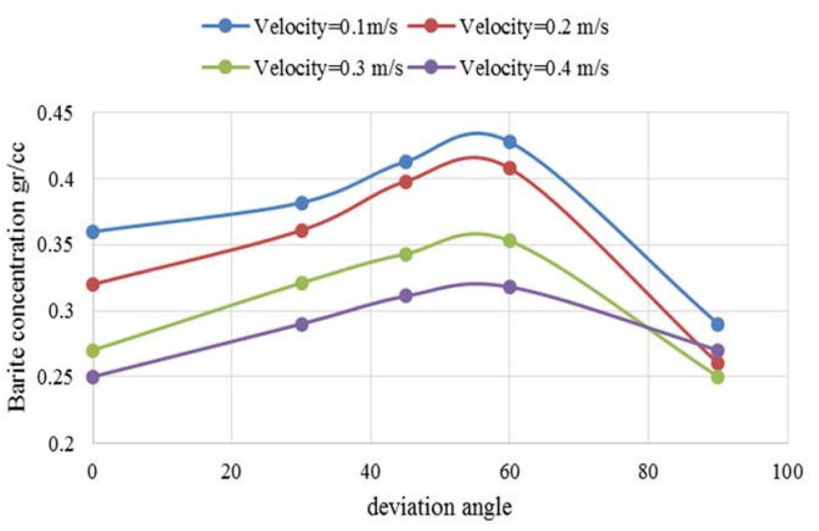

Fig. 7 Change in the amount of particles deposited in the circular space as a function of flow rate and deviation angle

can be observed, it seems that for all the examined deviation angles except $90^{\circ}$, increasing the flow rate leads to a reduction in precipitated barite particles. This observed trend can be related to this fact that as the flow rate increases, the agitation and movement of the particles enhance which can prevent fast precipitation of barite particles and consequently reduce the barite particle deposition. But on the other hand, further increase in the deviation angle from $60^{\circ}$ to $90^{\circ}$ leads to an increase in the precipitated amount of barite particle for flow rate of $0.4 \mathrm{l} / \mathrm{s}$.

Furthermore, the depicted results demonstrated that under constant flow rate condition (for all the examined flow rates of 0.1 to $0.4 \mathrm{l} / \mathrm{s}$ ), an increase in the deviation angle from $0^{\circ}$ to $60^{\circ}$ leads to an increase in the precipitation of barite particles since it can accelerate the movement of barite particles toward the lower section of the flow loop, while further increase in the deviation angle from $60^{\circ}$ to $90^{\circ}$ sharply reduces the amount of precipitated barite particles (see Fig. 7).

\section{Conclusions}

In the current work, the sedimentation behavior of barite particles was experimentally investigated using a series of systematic experiments using homemade laboratory flow loop equipment. In this way, several operating conditions such as flow rate, deviation angle and drilling string rotational speed were changed to find their possible effects on barite sag phenomenon. The performed experiments lead to results categorized as below:

- The amount of barite sag and the accumulated particles in the wells can be reduced and even eliminated by increasing the rotational speed of the drilling string.
- The maximum amount of precipitation of barite particles occurred in deviation angle of between $45^{\circ}$ and $60^{\circ}$.

- The vertical vectors created due to the rotation of the drilling string due to the low diameter of the barite particles will have a significant effect on the settlement of the deposited barite bed.

- By increasing the discharge flow rate from $0.19 \mathrm{l} / \mathrm{s}$ to $0.308 \mathrm{l} / \mathrm{s}$, barite deposition will face with a reduction.

- It would be possible to increase the precipitation rate of barite particles by changing the deviation angle to $45^{\circ}$, while further increase in deviation angle to value of $60^{\circ}$ would reduce the precipitation rate of barite particles.

- The precipitation rate of particles reduces as the inner pipe rotational speed increases which can be due to turbulent regime.

- Low rotational speed introduces a more significant effect on lowering the particles precipitation rates.

- Among the examined models, the Herschel-Buckley model can predict the behavior of the materials with higher accuracy which may be due to the presence of barite particles.

\section{Compliance with ethical standards}

Ethical statements The current manuscript is only submitted to the journal of "Journal of Petroleum Exploration and Production Technology" and would not be submitted to the other journal when the decision regarding this submission is completed.The current manuscript is original and performed by the authors of the manuscript in a clear way to enlighten concerns exited in the area of enhanced oil recovery based on chemical injection. Besides, it is not published elsewhere in any form or language (partially or in full) and is an expansion of our previous researches. It is not extracted from one study, and it is published from a series of studies performed regarding the EOR concerns. The obtained results and used procedure in the current manuscript are clearly stated and discussed making it easy for the readers to follow the current work. No data, text, or theories by others are presented as if they were the author's own ("plagiarism"). Proper acknowledgements are brought regarding the other works (this includes material that is closely copied (near verbatim), summarized and/or paraphrased), quotation marks (to indicate words taken from another source) used for verbatim copying of material, and permissions secured for material that is copyrighted.

Open Access This article is licensed under a Creative Commons Attribution 4.0 International License, which permits use, sharing, adaptation, distribution and reproduction in any medium or format, as long as you give appropriate credit to the original author(s) and the source, provide a link to the Creative Commons licence, and indicate if changes were made. The images or other third party material in this article are included in the article's Creative Commons licence, unless indicated otherwise in a credit line to the material. If material is not included in the article's Creative Commons licence and your intended use is not permitted by statutory regulation or exceeds the permitted use, you will 
need to obtain permission directly from the copyright holder. To view a copy of this licence, visit http://creativecommons.org/licenses/by/4.0/.

\section{References}

Hanson, P. M., Trigg Jr, T. K., Rachal, G., Zammora, M., (1990) Investigation of barite sag in weighted drilling fluids in highly deviated well. SPE 20423.

Hashemian, Y., Miska, S., Yu, M., Ozbayoglu, E., Takach, N., (2014) Experimental study and modelling of barite sag in annular flow. J. Canadian Petroleum Technology, SPE 173189

Kabanda P, Wang M (2017) Num m. Adv Num Anal. https://doi. org/10.1155/2017/2672438

Ribeiro JM Jr, Eler FM, Martins AL, Scheid CM, Calçada LA, Cruz Meleiro LA (2017) A simplified model applied to the barite sag and fluid flow in drilling muds: simulation and experimental results, oil \& gas science and technology—rev. IFP Energ Nouvelles $72: 23$

Mirjevardi N (2017) Comprehensive drilling engineering book. Azadeh Publication, Iran
Nguyen, T. C., Miska ,S., Yu, M., Takach, N., (2009) Predicting dynamic Barite sag in Newtonian oil based drilling fluids. SPE 12413.

Roohi, A., (2011) Investigation of sag Barite in Drilling Fluids and Providing an Innovative Method for Laboratory Examination of Barit sag in Static Conditions, The First National Congress of Iranian Drilling Industry.

Saasen, A., Liu, D., Marken, C. D., (1995) Prediction of barite sag potential of drilling fluids from rheological measurements. SPE 29410

Skalle P, Backe KR, Lyomov SK, Sveen J (1999) Barite Segregation in Inclined Boreholes. J Can Pet Technol 38:13

Yousefi Kashkah, M., (2013) Investigating the parameters of drilling on barit sag under laboratory conditions and comparing with field results, The first national conference on technology development in the oil, gas and petrochemical industries

Publisher's Note Springer Nature remains neutral with regard to jurisdictional claims in published maps and institutional affiliations.

\section{Affiliations}

\section{Saeed Zaker ${ }^{1} \cdot$ Pegah Sarafzadeh $^{2} \cdot$ Amin Ahmadi $^{3} \cdot$ Seyyed Hamid Esmaeili-Faraj ${ }^{4} \cdot$ Roohollah Parvizi $^{5}$}

Saeed Zaker

Saeedzaker91@gmail.com

Pegah Sarafzadeh

pegah.sarafzadeh@gmail.com

1 Science and Research Branch, Islamic Azad University, Sattari Expy, Tehran, Iran

2 Department of Chemical Engineering, Faculty of Al Zahra Shiraz, Fars Branch, Technical and Vocational University, Shiraz, Iran
3 Department of petroleum engineering, masjed-soleiman branch, Islamic azad university (I.a.u), Masjed-soleiman, Iran

4 Department of Material and Chemical Engineering, Shahrood University of Technology, 3619995161 Shahrood, Iran

5 Department of Chemistry \& Petroleum Engineering, Islamic Azad University, Qeshm Branch, Hormozgan, Iran 